\title{
Serapilheira produzida em um fragmento de uma Floresta Estacional Subtropical no estado do Rio Grande do Sul ${ }^{1}$
}

\author{
Hamilton Luiz Munari Vogel ${ }^{2}$; Leandro Homrich Lorentz ${ }^{3}$; Fabriciane Pereira Oliveira ${ }^{4}$
}

\begin{abstract}
Resumo: O presente estudo teve como objetivo, quantificar a produção anual de serapilheira e sua sazonalidade em um fragmento de floresta nativa localizado na região da Depressão Central do Estado do Rio Grande do Sul, no município de São Sepé. No interior desta floresta, em um local com condições homogêneas, foram alocadas de forma sistemática cinco parcelas de 20 m x 15 m, com 30 metros de distância entre si, onde foram distribuídos cinco coletores de serapilheira. Estes foram fixados no local a uma altura de um metro a partir do solo. A coleta de todo o material vegetal depositado pelas árvores nos coletores foi realizada mensalmente. No laboratório, as amostras foram separadas nas frações folhas, ramos finos (diâmetro $<0,5 \mathrm{~cm}$ ) e miscelânea, após, foram secas em estufa e pesadas em balança de precisão. Verificou-se para o período estudado uma deposição de $6,53 \mathrm{Mg} \mathrm{ha}^{-1}$ ano $^{-1}$ de serapilheira, onde as folhas foram responsáveis por $70 \%$, seguido da miscelânea com $18,6 \%$ e dos galhos finos com 11,4\%. A maior deposição foi observada na primavera, principalmente nos meses de outubro a janeiro, com pico de devolução em novembro.
\end{abstract}

Palavras - chave: Ciclagem de nutrientes; Folhas; Floresta Nativa.

\section{Litter fall production in a native forest in Depression Central region-RS}

\begin{abstract}
The present study aimed to quantify the annual litter fall and seasonality, in a fragment of native forest located in the Central Depression of Rio Grande do Sul, in São Sepé. The experiment was conducted in a fragment of Seasonal Semideciduous Forest. Inside this forest, in a place with homogeneous conditions were systematically allocated five plots of $20 \mathrm{~m} \times 15 \mathrm{~m}$ length, 30 meters away from each other, which were distributed five collectors in each plot, totaling 25 collectors. These were fixed in place to a height of one meter from the ground. The collection of all plant material deposited by the trees in the collectors was performed monthly. In the laboratory, the samples were separated into leaves, twigs (diameter $<0.5 \mathrm{~cm}$ ) and miscellaneous, were oven dried and weighed on a precision balance. It was found for the analyzed period an average annual of $6.53 \mathrm{Mg} \mathrm{ha}^{-1}$ litter fall; this total accounted for $70 \%$ leaves, followed by miscellaneous with $18.6 \%$ and twigs with $11.4 \%$. In the collection period of the study, there was a greater deposition of litter in the spring, especially in the months from October to January, with peak return in November.
\end{abstract}

Keywords: Nutrients cycling; Leaves; Native Forest.

\footnotetext{
${ }^{1}$ Recebido em 11.11.2014 e aceito para publicação como artigo científico em 25.02.2015.

2 Engenheiro Florestal, Prof. Dr. da Universidade Federal do Pampa (UNIPAMPA), Rua Antônio Trilha, 1847, CEP 97300-000, São Gabriel-RS. E-mail: <hamiltonvogel@unipampa.edu.br>.

${ }^{3}$ Engenheiro Agrônomo, Prof. Dr. da Universidade Federal do Pampa (UNIPAMPA), Rua Antônio Trilha, 1847, CEP 97300-000, São Gabriel-RS. E-mail: <leandrolorentz@unipampa.edu.br>.

${ }^{4}$ Graduanda do Curso de Engenharia Florestal da Universidade Federal do Pampa (UNIPAMPA), Rua Antônio Trilha, 1847, CEP 97300000, São Gabriel-RS. E-mail: <fabricianeoliveira@yahoo.com.br >.
} 


\section{Introdução}

A região da Depressão Central do Rio Grande do Sul, onde está inserido o presente estudo no município de São Sepé, possui forte tradição agropecuária, que pode ocasionar grandes impactos nos seus ecossistemas. Nesta região atualmente, restam poucas áreas com florestas nativas Estacionais remanescentes, formando fragmentos florestais com diferentes graus de perturbação, com poucos estudos desenvolvidos na região.

Com a fragmentação de habitats, várias mudanças ocorrem nos fatores bióticos e abióticos dos remanescentes de florestas (PORTELA e SANTOS, 2007); com relação aos abióticos, as principais alterações correm no microclima, como por exemplo, aumento da temperatura do ar, diminuição da umidade do ar e do solo, e aumento da intensidade dos ventos. Estas perturbações podem gerar alterações na produção de serapilheira na borda e no interior de fragmentos de florestas nativas, o que podem acarretar mudanças no banco de sementes e na germinação de plântulas, que garantem a regeneração natural da floresta.

A serapilheira é constituída principalmente por folhas, galhos finos $(<1 \mathrm{~mm})$, e resíduos (flores, frutos, sementes e restos vegetais nãoidentificáveis). A quantidade de material orgânico depositado pela serapilheira ao longo de um ano esta relacionada principalmente com as condições climáticas, sendo menor nas regiões frias e maior nas regiões equatoriais quentes e úmidas. Por exemplo, florestas situadas em regiões árticas ou alpinas produzem anualmente cerca de uma tonelada de serapilheira por hectare, florestas temperadas frias 3,5 toneladas, florestas temperadas quentes 5,5 toneladas e florestas equatoriais cerca de 11 toneladas (BRAY e GORHAM, 1964).

Em Florestas Estacionais no Sul do Brasil, a quantidade de material vegetal que cai do dossel formando a serapilheira atinge várias toneladas por hectare, conforme vários trabalhos já realizados, representando a principal via de retorno de material orgânico e nutrientes para a floresta (CUNHA, 1997; KÖNIG et al., 2002;
VOGEL et al., 2003; CALDEIRA, 2003; BRUN, 2004; VOGEL e SCHUMACHER, 2010; VOGEL et al., 2012).

A produção de serapilheira e a devolução de nutrientes em ecossistemas florestais constituem a via mais importante do ciclo biogeoquímico (relação dos nutrientes no esquema solo-plantasolo). Esse ciclo caracteriza-se, no primeiro estádio, pela absorção de nutrientes pelas raízes e por sua distribuição pelas diferentes partes da planta, sendo a taxa de absorção de nutrientes maior no período em que as árvores se encontram em estádio juvenil, o que corresponde ao período de maior produtividade dentro do processo de sucessão (KIMMINS, 1987). Após esse período, os nutrientes são transferidos novamente para o solo, pela deposição de serapilheira, lixiviação de folhas, ramos e troncos e pela ação da chuva, além do trabalho da fauna herbívora e da dispersão de frutos e sementes (POGGIANI e SCHUMACHER, 2000).

Reissmann e Wisnewski (2000) ressaltam que a absorção de nutrientes diretamente da serapilheira, representa um fluxo importante para atender a demanda nutricional das árvores. O tipo de vegetação e as condições ambientais são os fatores que mais influem na quantidade e qualidade do material que cai no solo (MOREIRA e SIQUEIRA, 2002).

Neste sentido, visando buscar um melhor entendimento das alterações dos aspectos ecológicos em fragmentos florestais, o presente estudo teve como objetivo principal quantificar a produção anual de serapilheira e sua sazonalidade nas frações folhas, galhos finos e miscelâneas em um fragmento de floresta nativa localizado na região da Depressão Central, no município de São Sepé - RS.

\section{Material e métodos}

O estudo foi desenvolvido em um fragmento de Floresta Estacional Semidecidual na localidade de Tupancy, localizado na região da Depressão Central do Estado do Rio Grande do Sul, no município de São Sepé, Rio Grande do 
Sul (Figura 1A). A área total aproximada do remanescente é de 40 hectares e está situada entre as coordenadas centrais de $30^{\circ} 12^{\prime} 45^{\prime \prime}$ e $30^{\circ} 13^{\prime} 09^{\prime \prime}$ de latitude sul e 53\%42'57' e $53^{\circ} 42^{\prime} 30^{\prime \prime}$ de longitude oeste, a aproximadamente 200 metros de altitude (Figura 1B). O fragmento encontra-se isolado das atividades agropastoris, sem interferência humana há pelo menos 50 anos.

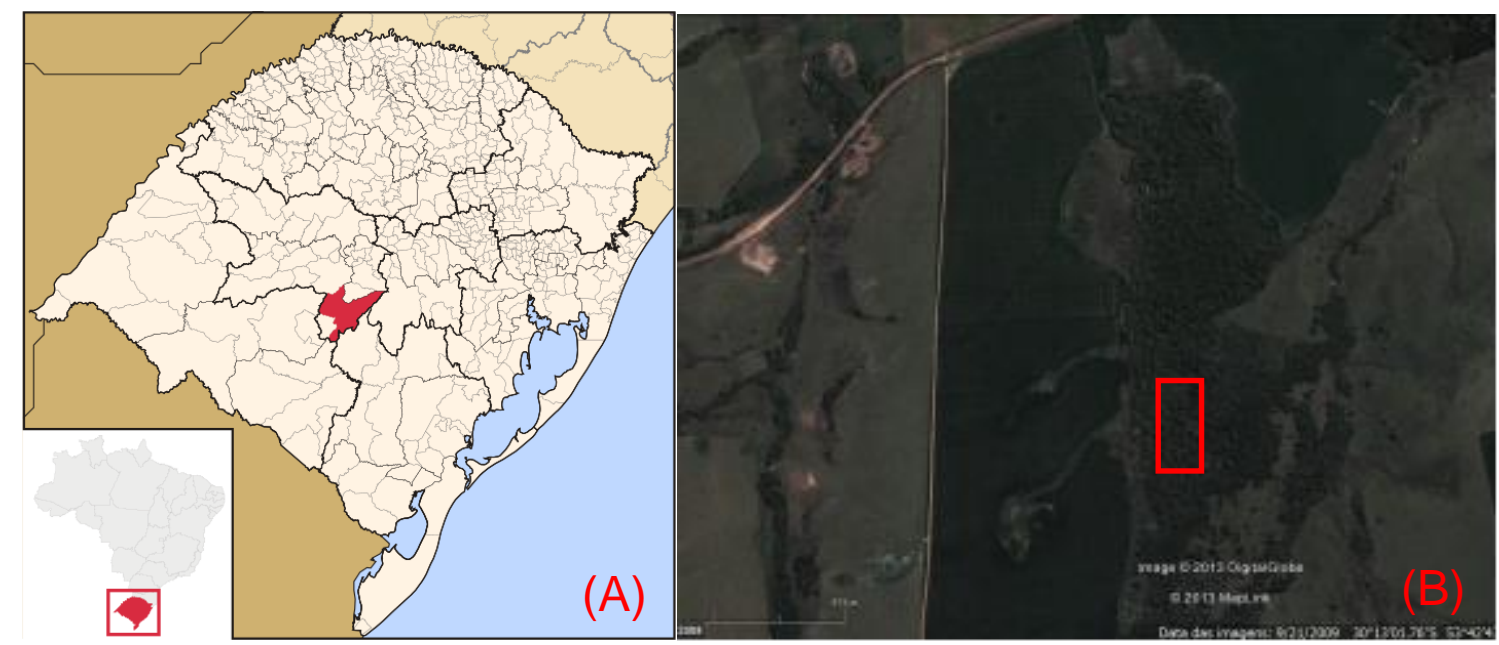

Figura 1: Mapa do Rio Grande do Sul, localização do município de São Sepé (A), e a localização do fragmento florestal estudado na Região da Depressão Central, São Sepé-RS (B) Fonte: Google Earth, 2013.

Figure 1: Map of Rio Grande do Sul, located in the municipality of São Sepé (A), and the location of the studied forest fragment in the Central Depression Region, São Sepé-RS (B). Source: Google Earth, 2013.

Conforme classificação de Köppen (1948), o clima na região é do tipo Cfa subtropical úmido. A temperatura média anual é de $19,3^{\circ} \mathrm{C}$ com temperatura média do mês mais quente superior a $24{ }^{\circ} \mathrm{C}$ no verão e $-3{ }^{\circ} \mathrm{C}$ no inverno. A precipitação média anual é relativamente alta com valores da ordem de $1500 \mathrm{~mm}$, distribuídas regularmente ao longo do ano.

O solo, de acordo com Streck et al. (2008), é classificado como Planossolo Háplico Eutrófico arênico, com textura superficial franco-arenosa no horizonte A e baixo teor de matéria orgânica.

A área apresenta afloramentos rochosos, especialmente na primeira faixa, instalada mais ao norte, também apresenta declive em direção oeste, onde se encontra um curso d'água.

Em relação à caracterização da composição florística e estrutural existem dois microsítios encontrados em função de algumas características edáficas: Grupo 1 - localizado em solo mais raso e pedregoso, e Grupo 2 localizado em solo mais profundo e de maior umidade (SILVEIRA, 2014). As espécies mais importantes do grupo 1 são Sorocea bonplandii, Matayba elaeagnoides, Thichilia claussenii, Cordia americana, Cordia ecalyculata e Helietta apiculata. E no grupo 2, destacaram-se Trichilia claussenii, Matayba elaeagnoides, Ocotea pulchella, Sorocea bonplandii, Helietta apiculata e Sebastiania commersoniana.

Para a coleta de serapilheira produzida, no interior do fragmento florestal, foram demarcadas cinco parcelas de $20 \mathrm{~m}$ x $15 \mathrm{~m}$ cada, alocadas de forma sistemática com 30 metros de distância entre elas. Em cada parcela foram distribuídos cinco coletores, totalizando assim 25 coletores.

Cada coletor foi constituído por uma moldura de ferro de forma circular, com $50 \mathrm{~cm}$ de diâmetro, e envoltos por uma tela com $2 \mathrm{~mm}$ de malha, com uma altura de um metro a partir do solo (Figura 2). 


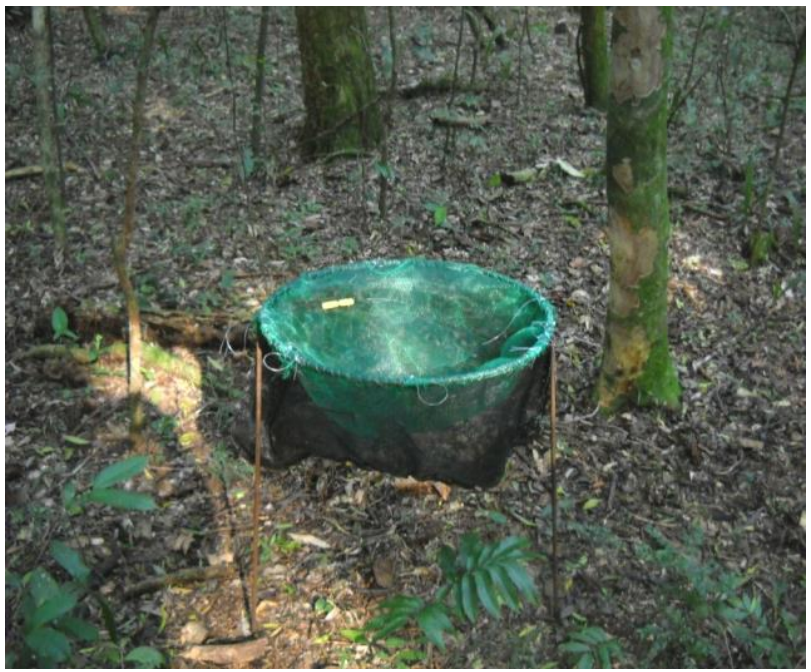

Figura 2: Aspecto de um dos coletores de serapilheira no fragmento florestal na Região da Depressão Central, São Sepé, RS, 2014.

Figure 2: Appearance of litter collectors in the forest fragment in the Central Depression region, São Sepé, RS, 2014.

As coletas foram realizadas mensalmente durante o período de um ano, com início no mês de maio de 2013 e término em abril de 2014, sendo que em cada coleta foi feita a retirada de todo o material vegetal depositado pelas árvores nos coletores, e colocado em sacos plásticos devidamente identificados. $\mathrm{O}$ material foi transportado até o laboratório, onde foi feita a separação das amostras, nas frações folhas, galhos finos (diâmetro $<0,5 \mathrm{~cm}$ ) e miscelânea, (cascas, sementes, flores e detritos não identificáveis), e acondicionadas em sacos de papel para posterior secagem em estufa de circulação e renovação de ar a $60^{\circ} \mathrm{C}$ até atingir peso constante. Após a secagem, o material foi pesado para obtenção do peso seco. Utilizou-se balança com precisão de $0,01 \mathrm{~g}$.

De posse dos pesos secos em gramas, estes foram extrapolados para $\mathrm{Mg} \mathrm{ha}{ }^{-1} \mathrm{ano}^{-1}$ pela seguinte expressão:

$$
\mathrm{PS}=\frac{\sum \mathrm{PMS} \times 10.000}{\mathrm{AC}}
$$

Onde:

PS: Produção de serapilheira $\left(\mathrm{Mg} \mathrm{ha}^{-1}\right.$ ano $\left.^{-1}\right)$

PMS: Produção mensal de serapilheira $\left(\mathrm{Mg} \mathrm{ha}^{-1}\right)$

AC: Área do coletor $\left(\mathrm{m}^{2}\right)$
Para verificar se houve influência do clima na deposição da serapilheira, os valores obtidos mensalmente foram correlacionados (correlação simples de Pearson a 1\% de probabilidade de erro) com a precipitação total mensal conforme dados da ANA (Agência Nacional de Água) para a região de São Sepé.

\section{Resultados e Discussão}

De acordo com a Tabela 1, a produção anual de serapilheira do fragmento de Floresta Estacional Semidecidual foi estimada em $6.531,9 \mathrm{~kg} \mathrm{ha}^{-1}$, variando ao longo do ano, onde a fração folhas representou a maior parte da serapilheira produzida ( $70 \%$ do total), seguido de miscelânea $(18,6 \%)$ e galhos finos $(11,4 \%)$. Estes valores fincaram próximo do encontrado por outros autores em diferentes locais e formações florestais nativas (KÖNIG et al., 2002; FIGUEREDO FILHO et al., 2003; TOLEDO et al. 2002; VITAL et al.. 2004; PEREIRA et al., 2008; ESPIG et al., 2009; ZHANG et al., 2014).

A produção de serapilheira em floresta nativa está relacionada ao estágio de desenvolvimento desta, conforme já relatado por Brun et al. (1999), que estudaram três fases sucessionais denominadas de capoeirão (27 anos), floresta secundária (50 anos) e floresta madura (+ de 100 anos), de uma Floresta Estacional Decidual em Santa Tereza-RS, relatando uma produção de serapilheira de 6,5, 7,4 e 9,7 $\mathrm{Mg} \mathrm{ha}{ }^{-1} \mathrm{ano}^{-1}$, respectivamente.

Avaliando a sazonalidade da produção de serapilheira numa Floresta Estacional Decidual no município de Santa Maria-RS, König et al. (2002) encontraram que a produção de serapilheira durante o ano de estudo foi de 9,2 $\mathrm{Mg} \mathrm{ha} \mathrm{ano}^{-1}$, sendo formada por $67,8 \% \mathrm{de}$ folhas, 19,3\% por galhos finos $(<1 \mathrm{~cm}$ de diâmetro) e 12,9\% de miscelânea (flores, frutos, sementes, outros materiais vegetais). Marafiga et al. (2012) avaliando a produção de serapilheira em um fragmento de Floresta Estacional Decidual no município de Itaara-RS na região central do RS, encontraram uma produção de 
serapilheira de 5,85 $\mathrm{Mg} \mathrm{ha}^{-1} \mathrm{ano}^{-1}$.

Tabela 1: Produção de serapilheira e suas frações na Floresta Estacional Semidecidual, RS, no período de maio de 2013 a abril de 2014.

Table 1: Litterfall and its fractions in Seasonal Semideciduous Forest, RS, from May 2013 to April 2014.

\begin{tabular}{ccccc}
\hline Mês & Folhas & Galhos & Miscelânea & Total \\
& & - & \\
Maio/13 & 179,3 & 18,4 & 23,9 & 221,6 \\
Junho/13 & 179,1 & 34,8 & 19,0 & 232,9 \\
Julho/13 & 167,0 & 21,5 & 22,2 & 210,7 \\
Agosto/13 & 298,3 & 76,8 & 10,4 & 385,4 \\
Setembro/13 & 414,4 & 44,8 & 11,9 & 471,1 \\
Outubro/13 & 707,4 & 43,5 & 60,6 & 811,5 \\
Novembro/13 & 852,7 & 28,4 & 159,0 & $1.040,1$ \\
Dezembro/13 & 611,1 & 95,8 & 256,8 & 963,7 \\
Janeiro/14 & 474,9 & 115,3 & 327,8 & 918,1 \\
Fevereiro/14 & 209,7 & 77,7 & 113,7 & 401,1 \\
Março/14 & 324,2 & 159,9 & 171,9 & 656,0 \\
Abril/14 & 154,2 & 29,9 & 35,6 & 219,7 \\
\hline Total & $\mathbf{4 . 5 7 2 , 2}$ & $\mathbf{7 4 6 , 8}$ & $\mathbf{1 . 2 1 3 , 0}$ & $\mathbf{6 . 5 3 1 , 9}$ \\
& $(70 \%)$ & $(11,4 \%)$ & $(18,6 \%)$ & $(100 \%)$ \\
\hline
\end{tabular}

Segundo Pinto et al. (2009), em dois trechos de Floresta Estacional Semidecidual, em distintos estádios sucessionais (inicial e maduro), da região de Viçosa-MG, verificaram que a queda anual de serapilheira foi de $6.31 \mathrm{Mg}$ $\mathrm{ha}^{-1}$ no trecho de floresta em seu estádio inicial e de $8.82 \mathrm{Mg} \mathrm{ha}^{-1} \mathrm{ano}^{-1}$ de floresta madura. Já Pereira et al. (2008), em um fragmento de Floresta Atlântica de encosta na Ilha da Marambaia, Mangaratiba-RJ, encontraram uma produção de serapilheira de $7,9 \mathrm{Mg} \mathrm{ha}^{-1} \mathrm{ano}^{-1}$, sendo a maior deposição verificada no mês de novembro e a menor em junho. Neste estudo a fração foliar foi a de maior contribuição em relação às demais com $66 \%$.

Custódio Filho et al. (1996) estudando a produção de serapilheira e retorno de nutrientes em uma Floresta Pluvial Atlântica (Floresta Ombrófila Densa), registraram uma produção anual de $6.01 \mathrm{Mg} \mathrm{ha}^{-1}$ de serapilheira, sendo que a fração folhas contribuiu com $72,73 \%$ do total, os ramos com $16,09 \%$ e outros componentes com 11,29\%. Já Britez et al. (1992) em uma Floresta Ombrófila Mista, no município de São
Mateus do Sul-PR, verificaram uma produção total de serapilheira de $6.526,7 \mathrm{~kg} \mathrm{ha}^{-1}$ ano $^{-1}$.

Em relação à sazonalidade da serapilheira, nota-se que a partir de outubro de 2013 até janeiro de 2014, houve um aumento significativo da deposição da serapilheira, com pico de deposição em novembro. Este comportamento reflete a retomada do crescimento das árvores que renovam suas copas e depositam consequentemente grandes quantidades de folhas senescentes neste período, típico de florestas Estacionais Subtropicais. Já as menores taxas de deposição ocorreram em abril/14, maio/13, junho/13 e julho/13 (Tabela 1 e Figura 3).

Resultados semelhantes foram observados por Brun et al. (1999), em três estágios sucessionais, em uma Floresta Estacional Decidual, no município de Santa Tereza-RS, observando que as maiores quedas de serapilheira ocorreram na primavera e verão, entre os meses de novembro e fevereiro, e as menores, no outono e inverno, entre os meses de abril e agosto. 


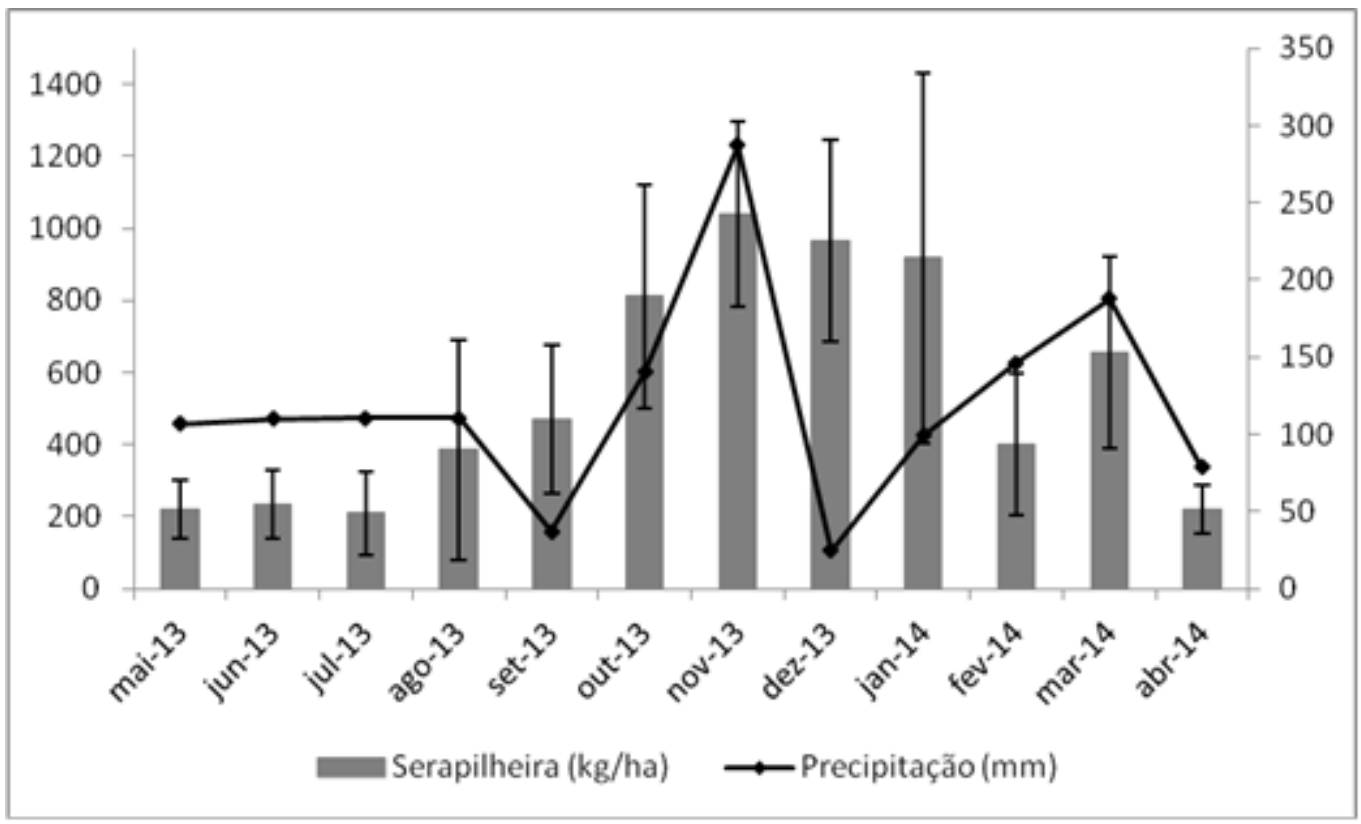

Figura 3: Serapilheira depositada no fragmento de Floresta Estacional Semidecidual, RS, no período de maio de 2013 a abril de 2014. Linhas na vertical representam a dispersão dos dados.

Figure 3: Litterfall in the Seasonal Semideciduous Forest, RS fragment, from May 2013 to April 2014. Vertical lines represent the dispersion of data.

Em estudo realizado por König et al. (2002), também em Floresta Estacional Decidual, próxima ao município de Santa Maria-RS, verificaram que os maiores picos de deposição da serapilheira ocorreram entre os meses de julho e setembro, com maior queda de folhas em setembro, quando se inicia o período de elevação da temperatura. Os autores ressaltam ainda que tal estratégia é característica das Florestas Estacionais Deciduais do sul do Brasil, nas quais uma estagnação do crescimento provocada pelo inverno faz com que ocorra a eliminação da folhagem senescente, visando o novo período de crescimento, que se inicia com a primavera, com o aparecimento de nova folhagem.

Uma maior deposição de serapilheira na primavera também foi observado por Figueiredo Filho et al. (2003), em uma Floresta Ombrófica
Mista, no sul do Paraná. Espig et al. (2009) em um remanescente de Mata Atlântica na região metropolitana de Recife-PE, ressaltam que a deposição de serapilheira foi maior nos períodos secos, e a sazonalidade influenciou o componente folha; estes autores encontraram uma deposição de serapilheira de $10,07 \mathrm{Mg} \mathrm{ha}^{-1}$ $\mathrm{ano}^{-1}$.

Em relação à correlação da deposição da serapilheira com a precipitação mensal, pode-se verificar que não houve interação significativa com a precipitação (Tabela 2 ). Porém pode-se observar uma tendência nos períodos de menos ocorrência de chuva, ocorrer uma menor produção de serapilheira, fato observado no período do inverno com temperaturas mais baixas (Figura 3).

Tabela 2: Coeficientes de correlação de Pearson, entre os componentes da serapilheira da Floresta Estacional Semidecidual e a precipitação, em São Sepé, RS, Brasil.

Table 2: Pearson correlation coefficients between the components of the Seasonal Semideciduous Forest litter and rainfall in Sao Sepé, RS, Brazil.

\begin{tabular}{ccccc}
\hline Variável climática & Folhas & Galhos finos & Miscelânea $^{\text {na }}$ & Serapilheira $^{1}$ \\
\hline Precipitação $(\mathrm{mm})$ & $0,37^{\text {n.s. }}$ & $0,03^{\text {n.s. }}$ & $0,09^{\text {n.s. }}$ & $0,3^{\text {n.s. }}$ \\
\hline
\end{tabular}

Em que: 1 = Serapilheira (soma das folhas + galhos finos + miscelânea); ns = não-significativo ao nível de 1\% de probabilidade de erro. 
Em Floresta Estacional Decidual próxima ao município de Santa Maria- RS, König et al. (2002) verificaram que a deposição de serapilheira não foi correlacionada significativamente com a precipitação, apresentando correlações negativas com a temperatura. Já Figueiredo Filho et al. (2003) obtiveram baixa correlação linear não significativa com a precipitação $(r=0,36)$ e com a temperatura $(\mathrm{r}=-0,10)$, em uma Floresta Ombrófica Mista no sul do Paraná.

Um aspecto importante a ser ressaltado está relacionado ao local onde são coletadas as informações climáticas, o que pode ter influenciado nos resultados de correlação. O ideal seria a disponibilidade de uma estação no próprio local do experimento e a continuidade da pesquisa num período maior, o que provavelmente poderá trazer informações mais seguras a respeito da correlação com estas variáveis, conforme já foi apontado por Figueiredo Filho et al. (2003) em seus estudos com serapilheira.

\section{Conclusões}

Verificou-se para o período estudado uma deposição média anual de $6,53 \mathrm{Mg} \mathrm{ha}^{-1} \mathrm{ano}^{-1} \mathrm{de}$ serapilheira; deste total as folhas foram responsáveis por $70 \%$, seguido da miscelânea com $18,6 \%$ e dos galhos finos com $11,4 \%$.

Houve maior deposição de serapilheira na primavera, principalmente nos meses de outubro a janeiro, com pico de devolução em novembro, representando um grande aporte de material orgânico para o ecossistema.

Não foi verificada uma correlação significativa entre a variável climática precipitação e a deposição de serapilheira.

\section{Agradecimentos}

Ao programa de bolsas de iniciação científica (PBDA) da UNIPAMPA pela concessão da bolsa de estudos.

Ao proprietário do local do experimento
Leandro Homrich Lorentz, pela logística e apoio prestados na coleta de dados.

\section{Referências}

BRAY, J. R.; GORHAM, E. Litter production in forests of the world. Advances in Ecological Research, Londres, v. 2, p. 101-157, 1964.

BRUN, E. J.; SCHUMACHER, M. V.; VACCARO, S. Produção de serapilheira e devolução de nutrientes em três fases sucessionais de uma Floresta Estacional Decidual no município de Santa Tereza (RS). In: SIMPÓSIO DE FERTILIZAÇÃO E NUTRIÇÃO FLORESTAL, 1., 1999, Piracicaba. Anais... Piracicaba, SP, 1999. p. 348-364.

BRUN, E. J. Biomassa e nutrientes na floresta Estacional Decidual, em Santa Tereza, RS. 2004. 136 f. Dissertação (Mestrado em Engenharia Florestal) - Universidade Federal de Santa Maria, Santa Maria. 2004.

BRITEZ, R. M.; REISSMANN, C.B.; SILVA, S. M.; SANTOS FILHO, A. Deposição Estacional de serapilheira e macronutrientes em uma floresta de Araucária, São Mateus do Sul, Paraná. Revista do Instituto Florestal, São Paulo, v. 4, n. 3, p. 766 -772, 1992.

CALDEIRA, M. V. W. Determinação de biomassa e nutrientes em uma floresta Ombrófila Mista Montana em General Carneiro, Paraná. 2003. 176 f. Tese (Doutorado em Ciências Florestais) Universidade Federal do Paraná, Curitiba. 2003.

CUNHA, G. C. Aspectos da ciclagem de nutrientes em diferentes fases sucessionais de uma floresta estacional do Rio Grande do Sul. 1997. 86 f. Dissertação (Mestrado em Ciências Florestais) - Escola Superior de Agricultura Luiz de Queiroz, Piracicaba, 1997.

CUSTÓDIO FILHO, A. et al. Produção de 
serapilheira e o retorno de macronutrientes em floresta pluvial atlântica - Estação Biológica de Boracéia (São Paulo - Brasil). Revista do Instituto Florestal, São Paulo, v. 8, n. 1, p. 116, 1996.

ESPIG, S. A. et al. Sazonalidade, composição e aporte de nutrientes da serapilheira em fragmento de Mata Atlântica. R. Árvore, Viçosa-MG, v.33, n.5, p.949-956, 2009.

FIGUEIREDO FILHO, A. et al. Avaliação estacional da deposição de serapilheira em uma floresta ombrófica mista localizada no sul do estado do Paraná. Ciência Florestal, Santa Maria, v.13, n.1, p.11-18, 2003.

KIMMINS, J. P. Forest ecology. New York: Collier Macmillan Canada, 1987; São Paulo: Ed. UNESP, 1993. 184 p.

KÖNIG, F. G. et al. Avaliação da sazonalidade da produção de serapilheira numa floresta Estacional Decidual no município de Santa Maria-RS. Revista Árvore, Viçosa, v.26, n.4, p. 429-435, 2002.

MARAFIGA, J.S. et al. Deposição de nutrientes pela serapilheira em um fragmento de Floresta Estacional Decidual no Rio Grande do Sul. Rev. Ceres, Viçosa, v.59, n.6, p.765-771, 2012.

MOREIRA, F. M. S.; SIQUEIRA, J. O. Microbiologia e bioquímica do solo. Lavras: Ed. UFLA, 2002. 626 p.

PEREIRA, M. G.; MENEZES, L. F.; SCHULTZ, N. Aporte e decomposição da serapilheira na floresta Atlântica, ilha da Marambaia, Mangaratiba, RJ. Ciência Florestal, v. 18, n. 4, out.-dez., 2008

PORTELA, R. C.; SANTOS, F. A. M. Produção e espessura da serapilheira na borda e interior de fragmentos florestais de Mata Atlântica de diferentes tamanhos. Revista Brasil. Bot. v.30, n.2, p.271-280, 2007

POGGIANI, F.; SCHUMACHER, M. V.
Ciclagem de nutrientes em Florestas Nativas. In: GONÇALVES, J. L. M.; BENEDETTI, V. Nutrição e fertilização florestal. Piracicaba: IPEF, 2000. p. 287-308.

PINTO, S.I.C. et al. Ciclagem de nutrientes em dois trechos de Floresta Estacional Semidecidual na reserva florestal Mata do Paraíso em Viçosa, MG, Brasil. R. Árvore, Viçosa-MG, v.33, n.4, p.653-663, 2009.

REISSMANN, C. B.; WISNIEWSKI, C. Aspectos nutricionais de plantios de Pinus. In: GONÇALVES, J. L. M.; BENEDETTI, V. Nutrição e fertilização florestal. Piracicaba: IPEF, 2000. p. 135-166.

SILVEIRA, B. D. Da, Fitossociologia, crescimento e competição de três espécies nativas da floresta estacional semidecidual da região central do Rio Grande do Sul. 2014, $106 \mathrm{f}$. Tese (Doutorado em engenharia florestal) - Universidade Federal do Paraná, Curitiba, 2014.

STRECK, E. V. et al. Solos do Rio Grande do Sul. 2. ed. Porto Alegre: EMATER/RS-ASCAR, 2008. 222 p.

TOLEDO, L. O.; PEREIRA, M. G.; MENEZES, C. E. G. Produção de serapilheira e transferência de nutrientes em florestas secundárias localizadas na região de Pinheiral, RJ. Ciência Florestal, Santa Maria, v. 12, n. 2, p. 9-16, 2002.

VITAL, A. R. T. et al. Produção de serapilheira e ciclagem de nutrientes de uma floresta estacional semidecidual em zona riparia. Revista Árvore, v.28, n.6, p.793-800, 2004.

VOGEL, H. L. M.; SCHUMACHER, M. V.; LOPES, V. G. Biomassa e nutrientes na serapilheira de uma floresta Estaconal Decidual. In: $9^{\circ}$ Congresso Florestal Estadual do Rio Grande do Sul, 2003, Nova Prata. Anais... Nova Prata, RS, 2003.

VOGEL, H. L. M.; SCHUMACHER, M. V. 
Quantificação dos nutrientes na serapilheira em um fragmento de floresta Estacional Semidecidual em São Gabriel-RS, Brasil. In: FertBio2010, 2010, Guarapari. Anais... Guarapari, ES, 2010.

VOGEL, H. L. M.; GOI ROTT, A.; MOTTA, M. S. M.; SCHUMACHER, M. V. Produção de serapilheira na borda e no interior de um fragmento de floresta nativa na região do Bioma Pampa. In: $11^{\circ}$ Congresso Florestal Estadual do Rio Grande do Sul, 2012, Nova Prata. Anais... Nova Prata, RS, 2012.

ZHANG, H.; YUAN, W.; DONG, W.; LIU S. Seasonal patterns of litterfall in forest ecosystem worldwide. Ecological Complexity, v.20, n.1, p.240-247, 2014. 